\title{
Aeroallergene als Auslöser von Berufskrankheiten
}

\begin{abstract}
Bei Inhalationsallergien als Berufskrankheit denkt man wahrscheinlich zuerst an Bäcker und Friseure. Aber auch an zahlreichen anderen Arbeitsplätzen drohen Sensibilisierungen gegen die unterschiedlichsten Stoffe.
\end{abstract}

Tatsächlich war das Bäckerasthma durch Mehl- und Mehlprodukte mit einem Anteil von $60 \%$ im Jahr 2014 die häufigste anerkannte Berufskrankheit durch luftübertragene Allergene, berichtete Prof. Monika Raulf vom Institut für Prävention und Arbeitsmedizin der Deutschen gesetzlichen Unfallversicherung an der Ruhr-Universität Bochum. Dabei findet man nicht nur Sensibilisierungen gegenüber Weizen- und Roggen - auch zahlreiche andere beim Backen eingesetzte Stoffe wie andere Getreidearten, Ei, Soja, Milben, Getreideschädlinge oder Nüsse können bei Allergikern zum Problem werden.

Eine wichtige Rolle als Allergieauslöser spielen zunehmend auch meist auch Mikroorganismen gewonnene Enzyme, die u. a. bewirken sollen, dass alle Brötchen und Broten bei einem standardisierten Backprozess möglichst gleich geformt sind. Dazu gehört zum Beispiel die $\alpha$-Amylase, gegen die sich bei $16 \%$ der Bäcker mit allergischen Beschwerden IgE-Antikörper nachweisen lassen. Auch gegen andere Enzyme wie Cellulase, Xylanase oder Glucoamylase werden zunehmende Sensibilisierungen nachgewiesen.

\section{Auch verkapselte oder verflüssigte Enzyme bleiben problematisch}

Das Problem mit den Enzymen kennt man auch aus der Waschmittelherstellung. Nachdem etwa ab 1960 den Waschmitteln verschiedene Proteasen zur besseren Fleckentfernung beigefügt wurden, beobachtete man unter den Mitarbeitern einen deutlichen Anstieg von Sensibilisierungen und allergischen Erkrankungen. In den 1970er Jahren fing man dann an, die Enzyme zu verkapseln, was das Problem zuerst zu lösen schien. Aktuellere Untersuchungen haben aber gezeigt, dass die Sensibilisierungsraten gegen Enzyme trotz der Verkapselung relativ hoch bleiben, so die Expertin [1]. Auch die Anwendung der Enzyme in flüssiger Form scheint keine Lösung zu sein; auch hier ließ sich ein relevanter Anteil von Sensibilisierungen nachweisen [2]. Auch in anderen Arbeitsbereichen spielen Aeroallergene eine wichtige Rolle bei Allergie-bedingten Berufskrankheiten. Hier nannte die Kollegin beispielsweise Arbeiter in Gewächshäusern, bei denen man einen relativ hohen Anteil von Sensibilisierungen gegen ansonsten eher unproblematische Pollen von Blumenkohl, Brokkoli, Paprika und Tomaten findet.

Zunehmend sind auch Mitarbeiter in holzverarbeitenden Betrieben von Allergien betroffen - allein in Deutschland sind das etwa 700.000 Menschen. Die höchsten Sensibilisierungsraten findet man hier bei tropischen Hölzern wie Abachi oder Kambala - bei den heimischen Hölzern ist der Buchsbaum führend.

Maria Weiß

\footnotetext{
Referenzen:

1. Cullinan $\mathrm{P}$ et al. An outbreak of asthma in a modern detergent factory. Lancet. 2000;356:1899-900

2. van Rooy J et al. A cross sectional study among workers exposed to liquid dertergent enzymes. Occup Environ Med. 2009;66:759-65
}

Quelle: Symposium AllergoCompact „Neue Aeroallergen mit regionaler, nationaler/globaler Verbreitung“, Deutscher Allergiekongress, 30.9.2016, Berlin

\section{Experten fordern sichere Finanzierung von Pollen-Messstellen}

\author{
Pollenallergien sind weiter auf dem Vormarsch - vor \\ allem in den Großstädten nimmt die Sensibilisie- \\ rungs- und Allergierate zu. Durch die "Hygiene-Hy- \\ pothese" ist das nicht allein zu erklären und auch der \\ Verzicht auf städtisches Grün ist keine Lösung. Wich- \\ tig bleibt weiterhin die Messung des Pollenfluges - \\ hier ist in der Bundesrepublik aber die Finanzierung \\ gefährdet.
}

Die Hygiene-Hypothese musste lange herhalten, den weltweiten stetigen Anstieg von Heuschnupfen und allergischem Asthma zu erklären. Sie bietet aber keine Erklärung für den Anstieg dieser Erkrankungen seit 1970, sagte Prof. Dr. rer. pharm Jeroen Buters vom Lehrstuhl für molekulare Allergologie der TU München. Wesentlich Faktoren der Hygiene wie feste Häuser und sauberes Trinkwasser gibt es in Deutschland immerhin schon seit Anfang des 20. Jahrhunderts. 